\title{
Design approach of digital numeration training for students in a primary school
}

\author{
Adrian Roussel-Fayard ${ }^{1}$, Nadine Vigouroux ${ }^{1}$, Frédéric Vella ${ }^{1}{ }^{*}$, Jean-François Camps ${ }^{2}$ \\ and Charlotte Tabarant ${ }^{3}$ \\ ${ }^{1}$ IRIT,CNRS, UPS, 118 Route de Narbonne, \\ F-31062 Toulouse CEDEX 9, France \\ $\{$ Nadine.Vigouroux, Frederic.Vella\}@irit.fr \\ ${ }^{2}$ URI Octogone-Lordat, UT2J, 5, allée Antonio Machado, \\ 31058 Toulouse CEDEX 9, France \\ jcamps@univ-tlse2.fr \\ ${ }^{3}$ academic's direction, french national's education \\ cosel@hotmail.fr
}

\begin{abstract}
This article report the principles and the design of HMK-Learning, a digital tool for students at primary schools in France. The design is based on Mounier's numeracy work in didactics. Then, we describe the questionnaire design method to study the usability of HMK-Learning. Next, we present the questionnaire results answered by four teachers of primary schools. Finally, we discuss them from the point of view of the design of HMK-Learning and the pedagogical questions they raised. This paper also highlights the highly important role of didactics in the process of designing a digital tool for numeracy learning for primary school children that we have identified in the answers of the usability questionnaires.
\end{abstract}

Keywords: Centered design· usability· digital numeration· primary school

\section{Introduction}

According to the results of the Trends in International Mathematics and Science Study survey, carried out in May 2019 on writing in figures a sample of 4,186 (9 years old) children (primary school), France ranks last in the European Union countries for the level of knowledge in mathematics. In France, the Villani-Torossian [1] report "21 measures for the teaching of mathematics" stated learning difficulties from primary school onwards (6 to 10 years old). These relate to acquiring the sense of numbers, counting, memorizing the names of numbers, writing in figures and the transcoding

\footnotetext{
* Please note that the LNCS Editorial assumes that all authors have used the western naming convention, with given names preceding surnames (first name then last name). This determines the structure of the names in the running heads and the author index. No academic titles or descriptions of academic positions should be included in the addresses. The affiliations should consist of the author's institution, town, and country.
} 
between oral numeration (one, two, etc.) and written numeration $(1,2$, etc.). One of the recommendations in the report concerns the meaning of the four operations (addition, subtraction, multiplication and division) and the teaching of the quantities and measures in primary school that should support number and operation sense. According to E. Mounie, (2016) [2] "The problem then arises, with 6 years old pupils, of showing that numbers refer to units of numeration, tens and simple units for the acquisition of skills to be built by students in primary school." To overcome these difficulties, we wish to approach the learning of numeracy through a digital application.

Several recent studies have examined the effects of digital applications on students' skills. Drijvers [4] wrote that "the success of digital technology in mathematics education include the design of the digital tool and corresponding tasks exploiting the tool's pedagogical potential, the role of the teacher and the educational context". Geiger et al [6] presented a model of numeracy based on the use of digital technologies. They also demonstrated the good influence of digital tools on student's development of skills and mathematical knowledge. Hodaňová et al. [5] also reported that the efficient use of digital technologies is undoubted a prerequisite for both quality education. These same authors suggested digital technologies in mathematics teaching at primary schools belong to innovative methods and activity forms.

Our hypothesis is that the design of interactive digital tools integrating Mounier's [2] numeracy work could be more efficient for students at primary schools in France. The aim of this paper is to describe the methodology used to design the application HMKLearning for pupils at primary school. Then, we will describe the survey design method to study the usability of HMK-Learning. Finally, we will present the results of the usability study and discuss them from the point of view of the design of HMK-Learning and the pedagogical questions they raised.

\section{Related work}

Evaluating the usability of interactive systems is no longer a new scientific issue but remains a scientific challenge [14] for educational software for children in primary school. According to Nielsen [11] usability is about learnability, efficiency, memorability, errors, and satisfaction. However, the definition of usability from ISO 9241-11 [15] is "the extent to which a product can be used by specified users to achieve specified goals with effectiveness, efficiency and satisfaction in a specified context of use". Several methods are available to measure the usability. One of them is Nielsen's heuristics [11] which allows to identify usability problems in the process of designing an interactive system. Another is Heuristic Evaluation for Child E-learning (HECE) [9] based on Nielsen's heuristics adapted to children and e-learning applications. In parallel to these heuristic-centered approaches, other classically methods are used during user tests: interviews, observations by experimenters in use situations, surveys, activity logs. The SUS (System Usability Scale) [7] is widely used because it easily provides an interpretable score [13]. However, children cannot use this survey in the reading learning phase. Child-friendly tools for assessing the learning environment are relatively rare. Khanum and Trivedi [10] analyzed different assessment techniques (Think Aloud (His reasoning, thread of thought.), Constructive Interaction (interaction between two testers who interact), etc.) to determine which are the most suitable for children according to 
their age. These authors also suggest crossing several methods in order to have more results that are relevant and recommend a series of recommendations for the conduct of the experiments. Evaluation involving end-users during the co-design phases are highly recommended to identify usability problems precisely when using the application when it is possible.

Within the framework of the design of the HMK-Learning software, we have chosen to involve the teachers of the primary schools in the iteration of HMK-Learning design and the usability of designs.

\section{Design of HandyMathKey-Learning}

In collaboration with a group of teachers eventually called Villani Torossian, we implemented a participatory design method for the HMK-L application. The constraints of use were that primary school children did not have a sufficient reading level, and that the interface should be simple to use and fun. The particularity of our approach concerns the involvement of the ecosystem in the sense of Guffroy et al. [3].

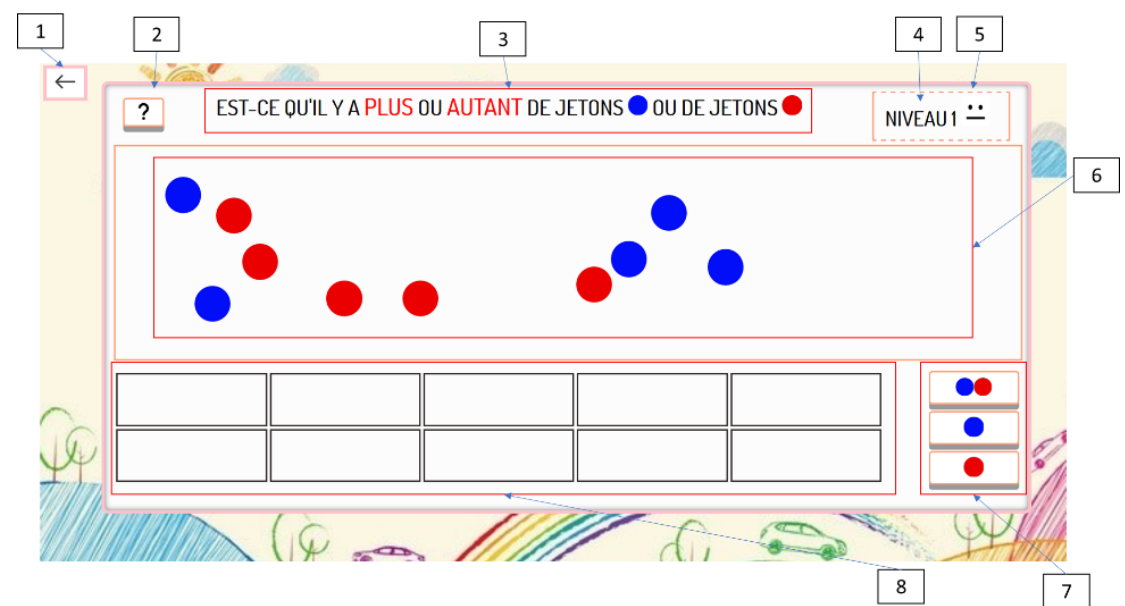

Fig. 1. The number comparison exercise has several interactive components: 1) the button to return to the home page; 2) the help button for handling the tokens; 3) the textual instruction; 4) the level of the exercise; 5) the pictogram representing the child's progress in the exercise; 6) the 2 classes of tokens to be compared; 7) the button to be selected for the choice of the correct answer; an animation and audio feedback are given according the answer 8) the digital tape to help the pupils visualise the quantity of tokens.

The ecosystem is a group of people who express needs in the place of end users when they are unable to formulate the demand: lack of knowledge, difficulties in expressing themselves, etc. The ecosystem is composed of mathematic's didactical expert (five teachers in primary school and one expert mathematical referent). A first activity, the comparison of numbers, has been prototyped. The ecosystem has defined the specification based on Mounier's work [2] on learning to number, gave feedback on the proposals 
for interactive models during two focus groups, discussed the choices on how to formulate the instructions, the representations of the buttons and the overall structure of the HMK-L interface (Fig. 1) represents the first iteration of the number comparison interface.

\section{$4 \quad$ Design of the Usability Method}

\subsection{Approach to designing the usability survey}

There are also many standardized surveys for assessing usability, notably the System Usability Scale (SUS) [7] or the Heuristic Evaluation for Child E-learning (HECE) [9]. User tests are not limited to usability surveys [10]. However, in the health context of COVID in March 2020, the survey is the most suitable tool for remote evaluation. This makes it possible to overcome the heavy constraints associated with face-to-face work (social distancing, cleaning of experimental equipment, etc.). The Primary teachers carried out usability tests. They will use HMK-L as a teaching tool in their ordinary classroom

A multidisciplinary team ( 1 cognitive psychology researcher, 2 researchers and a student in human-computer interaction) has designed the survey. An expert mathematical referent and two primary school teachers of her working group have checked the comprehension (objective of the question, meaning of words) of the first version of the survey. We corrected ambiguous questions so that the evaluation could be carried out without the presence of the experimenter.

\subsection{Content of the survey}

To ensure that we addressed all aspects of usability, the design of the survey was based on the heuristic set, HECE adapted to the evaluation of e-learning applications for children. We then classified the 21 Alsumait's heuristics by grouping them according to Nielsen's 10 heuristics. Then we distributed the 47 criteria (decomposition of those heuristics) of HECE in regard of Nielsen's ten reference heuristics.

To complete the survey, users had to perform a scenario. This scenario is structured into 8 tasks divided into sub-tasks, covering all the functionalities we want to evaluate. These tasks are: Choice of interaction technique, Discovery of the interface, Exercise using the help button, Unassisted exercise, Exercise with error, Go to next level, Exit the application, Free use. A question section follows the guidelines of the subtask to be performed. The survey consists of semi-open questions and questions with a 6 item Likert scale (absolutely not good, not good, rather good, good, and absolutely good). The Table 1 presents how questions are linked to Nielsen's heuristics and Alsumait's criteria. 
Table 1. Links between Nielsen's heuristics, Alsumait's criteria and questions of the survey.

\begin{tabular}{|c|c|c|c|}
\hline Tasks & $\begin{array}{l}\text { Nielsen's } \\
\text { Heuristics }\end{array}$ & Alsumait's criteria & Question \\
\hline \multirow[t]{2}{*}{$\begin{array}{l}\text { Discover } \\
\text { exercise } \\
\text { layout }\end{array}$} & $\begin{array}{l}\text { Match between } \\
\text { system and the } \\
\text { real world }\end{array}$ & $\begin{array}{l}\text { All learning objects } \\
\text { and images should be } \\
\text { recognizable and } \\
\text { understandable to the } \\
\text { child, and speak to } \\
\text { their function }\end{array}$ & $\begin{array}{l}\text { Do you understand the } \\
\text { meaning of all the } \\
\text { elements on the screen? } \\
\text { If not, which ones? }\end{array}$ \\
\hline & & $\begin{array}{l}\text { The e-learning } \\
\text { program interface } \\
\text { employs simple } \\
\text { words, phrases and } \\
\text { concepts familiar to } \\
\text { the child and makes } \\
\text { information appear in } \\
\text { a natural and logical } \\
\text { order }\end{array}$ & $\begin{array}{l}\text { Is the page layout } \\
\text { understandable? If not, } \\
\text { why not? } \\
\text { Is the structure of the } \\
\text { screen layout logical } \\
\text { and understandable? }\end{array}$ \\
\hline $\begin{array}{l}\text { View text } \\
\text { instruction and } \\
\text { answer buttons }\end{array}$ & $\begin{array}{l}\text { Visibility of System } \\
\text { Status }\end{array}$ & $\begin{array}{l}\text { The child understands } \\
\text { all terminology used in } \\
\text { the program }\end{array}$ & $\begin{array}{l}\text { What do you think of } \\
\text { the shape of the answer } \\
\text { buttons in terms of } \\
\text { readability and } \\
\text { comprehension? }\end{array}$ \\
\hline
\end{tabular}

The survey contains 65 questions using $76.6 \%$ of the criteria. Table 2 gives the details of the rate of use of the criteria.

Table 2. Percentage of Nielsen's Heuristics used in the survey.

\begin{tabular}{cccc}
\hline Nielsen's Heuristics & $\begin{array}{c}\text { Number of } \\
\text { criteria used }\end{array}$ & $\begin{array}{c}\text { Number of } \\
\text { criteria by } \\
\text { category }\end{array}$ & $\begin{array}{c}\text { Percentage use } \\
\text { of criteria }\end{array}$ \\
\hline Visibility of System Status & 6 & 8 & $75 \%$ \\
Match between system and & 4 & 5 & $80 \%$ \\
the real world & 3 & 4 & $75 \%$ \\
User Control freedom & 4 & 6 & $66,67 \%$ \\
Consistency and standards & 3 & 4 & $75 \%$ \\
Error prevention & & &
\end{tabular}




\begin{tabular}{cccc}
$\begin{array}{c}\text { Recognition rather than } \\
\text { recall }\end{array}$ & 3 & 4 & $75 \%$ \\
$\begin{array}{c}\text { Flexibility and efficiency of } \\
\text { use }\end{array}$ & 7 & 8 & $87,5 \%$ \\
$\begin{array}{c}\text { Aesthetic and minimalist } \\
\text { desi, }\end{array}$ & 3 & 3 & $100 \%$ \\
$\begin{array}{c}\text { Help users recognize, } \\
\text { diagnose and recover from } \\
\quad \begin{array}{c}\text { errors } \\
\text { Help and documentation }\end{array}\end{array}$ & 0 & 1 & $0 \%$ \\
\hline
\end{tabular}

\section{$5 \quad$ Analysis of survey}

The usability' survey were send to 4 teachers during the containment (October November 2020 in France). Teachers were invited to explore and use the HMK-Learning application and then follow the scenario associated with the survey before answering it. The table 3 summarizes relevant results from the analysis of the survey for the second iterative design of HMK-Learning.

Table 3. Some relevant results of the usability surveys by 4 teachers.

\begin{tabular}{|c|c|}
\hline $\begin{array}{l}\text { Interface elements and } \\
\text { pedagogic strategy }\end{array}$ & Evaluation report \\
\hline $\begin{array}{l}\text { Visual aspect of the } \\
\text { interface }\end{array}$ & $\begin{array}{l}\text { Pleasant, airy, understandable, playful and well- } \\
\text { structured; }\end{array}$ \\
\hline Textual instructions & $\begin{array}{c}\text { Understandable, presentation in sound modality } \\
\text { required }\end{array}$ \\
\hline Spatial layout of tokens & $\begin{array}{l}\text { Good distribution, token overlapping to be avoided, } \\
\text { no need of audio feedback }\end{array}$ \\
\hline Feedback & $\begin{array}{l}\text { Progress scale for exercises is suitable, feedback of } \\
\text { success or failure is also appropriate }\end{array}$ \\
\hline $\begin{array}{l}\text { Strategy to compare the } \\
\text { token collection }\end{array}$ & $\begin{array}{l}\text { Need to add different strategies : clustering by sets } \\
\text { ( } 5 \text { or } 10 \text { tokens) or pair to pair comparison }\end{array}$ \\
\hline Selection mode of tokens & Allow several strategies (one by one, by set) \\
\hline Help & $\begin{array}{l}\text { Need to be redesigned from a pedagogical point of } \\
\text { view }\end{array}$ \\
\hline
\end{tabular}

The following section gives some more verbal results from the questionnaires that complete the analysis.

According to strategy to compare the token collection: Respondents reported that pupils using HMK-L seemed not to develop an optimized strategy involving clustering 
of tokens to compare bigger collections. We also ask the question of simultaneous token selection or not to ease the comparison on higher numbers than 19. 2 teachers are for selection per pack of 5 or 10 faster; the other two are against it because it is too complex but less adapted to the term-to-term comparison

The Progress scale_for exercises is suitable for three of the four teachers. The last suggests improving the smiley representation (number 5 on Fig. 1) to better distinguish the levels of exercise. The animations displayed according to the student's results are very playful and fun for 3 of respondents. The fourth teacher suggests a more encouraging animation when a wrong answer to the exercise is given. The usefulness of the sound associated with the animated image is also mentioned.

The arrows for navigation through the exercise (go to the next exercise, repeat the exercise, go to the next level of difficulty) are affordant. The role of the digital tape is also understandable for the pupils according to the 4 teachers. According to the 4 teachers respondents, the HMK-L application is adapted for children at this educational level as shown in this verbatim by one of the fourth teachers: "Yes: possibility to repeat the levels if there is a lack of confidence and possibility to pass to the next level quickly enough for those who are more at ease".

The help device is an essential function: the analysis of the results shows that it need to be context-specific, to depend on the level of the exercise, to be adapted to the pupil' skills and to take into account the various pedagogical strategies.

Analyses of this usability survey had an unexpected and interesting result. More than ergonomics data, results led to didactic and pedagogical debates particularly on instructions'rewording (number 3 on Fig. 1) on and the strategical use of the digital tape (number 8 on Fig. 1)

\section{Conclusion and Perspective}

Based on the didactic work of Mounier's numeration we co-design the HMKLearning with the teachers of primary school. Then, we implemented a method for designing a usability survey based on Alsumait's and Nielsen's heuristics. Four primary school teachers answered this survey. The analysis was very rich and usable from two angles: 1) redesign of interaction components (instruction, progress feedback, etc.) to improve ergonomics and accessibility of HMK-Learning; 2) implementation of pedagogical strategies (token comparison strategies, formulation of instruction, help, etc.).

Based on this first ergonomic study and to become a more inclusive and adapted tool at school, HMK-L need further implementations. It is of interest to note that ergonomic data participated to didactic reflection on strategies, procedure.... This unexpected result could involve evolutions in usability studies by integrating some didactic 'like heuristics in future studies. This project will be ongoing by analyzing utility and usefulness in context with pupil's interactions, learning performances. 


\section{Acknowledgment}

This project was partly funded by the MSHS-T in Toulouse. The authors would like to thank the teachers from the primary schools who participated in the HMK-Learning specifications and who answered the usability survey.

\section{References}

1. Villani, C., Torossian, C. : 21 mesures pour l'enseignement des mathématiques. Ministère de l'Éducation nationale. Paris. http://cache.media.education.gouv.fr/file/Fevrier/19/0/Rapport_Villani_Torossian_21_mesures_pour_enseignement_des_mathematiques_896190.pdf, (2018).

2. Mounier, E. : Nouveaux outils d'analyse des procédures de dénombrement pour explorer leur lien avec la numération écrite chiffrée et la numération parlée. Recherches en didactique des mathématiques, 36(3), 347-396 (2017).

3. Guffroy, M., Vigouroux N., Kolski C, Vella F., and Teutsch Ph.: From Human-Centered Design to Disabled User \& Ecosystem Centered Design in Case of Assistive Interactive Systems, International Journal of Sociotechnology and Knowledge Development (IJSKD) 9, no. 4 (2017): 28-42 (2017).

4. Drijvers, P.: Digital Technology in Mathematics Education: Why It Works, Selected Regular Lectures from the 12th International Congress on Mathematical Education, 135 - 151 (2015), DOI, 10.1007/978-3-319-17187-6_8

5. Jitka Hodaňová, Marek Škultéty, Hana Hyksová, Digital technologies in mathematics teaching at primary schools, Conference: 11 th Annual International Conference on Education and New Learning Technologies,Palma de Mallorca, Spain, July, DOI :10.21125/edulearn.2019.1057 (2019).

6. Geiger, V., Goos, M. \& Dole, S.: The Role of Digital Technologies in Numeracy Teaching and Learning. Int $J$ of Sci and Math Educ 13, 1115-1137 (2015). https://doi.org/10.1007/s10763-014-9530-4

7. Brooke, J.: SUS: a "quick and dirty" usability scale. In P. W. Jordan; B. Thomas; B. A. Weerdmeester; A. L. McClelland (eds.). Usability Evaluation in Industry. London: Taylor and Francis (1986).

8. Quiñones, D.,et Rusu, C.. : How to develop usability heuristics: A systematic literature review. Computer Standards \& Interfaces, vol. 53, 89-122 (2017).

9. Alsumait, A.,et Al-Osaimi, A.: Usability heuristics evaluation for child e-learning applications. In : Proceedings of the 11th international conference on information integration and web-based applications \& services. 425-430 (2009).

10.Khanum, M.,A et Trivedi, M.C. : Take care: a study on usability evaluation methods for children. arXiv preprint arXiv:1212.0647 (2012).

11.Nielsen, J.: 10 usability heuristics for user interface design. Nielsen Norman Group, vol. 1, no 1 (1995).

12.Khanum M. A., Trivedi M. C.: Take care: a study on usability evaluation methods for children, arXiv preprint arXiv:1212.0647 (2012).

13.Lewis, J.R. \& Sauro, J.: The factor structure of the system usability scale (PDF). International conference (HCII 2009), San Diego CA, USA (2009).

14.Baraudon, C. : Principes de conception et de validation d'un outil d'évaluation de l'utilisabilité perçue adapté à des enfants, Septièmes Rencontres Jeunes Chercheurs en EIAH (RJC EIAH 2018), Besançon, France, hal-01769535 (2018).

15.ISO/IEC. "9241-11 Ergonomic Requirements for OfTice Work with Visual Display Terminals (VDT)s-Part II Guidance on Usability," ISO/IEC 9241-11,1998 (E). 